\title{
SCIENCE CHINA \\ Life Sciences
}

\section{Profile of Peng Li}

Dr. Peng Li received her B.S. degree from Beijing Normal University (China) in 1987. In 1988, she joined the Department of Biochemistry, University of Texas Southwestern Medical Center at Dallas (USA) as a CUSBEA (China-United States Biochemistry Examination and Application) student. In 1995, she received her Ph.D. degree from University of California at San Diego (U.S.A). She then did her post-doctoral training in Howard Hughes Medical Institute, University of Texas Southwestern Medical Center at Dallas (U.S.A) and Institute of Molecular and Cell Biology (Singapore) between 1996 and 1997. She became assistant professor and principal investigator in the Institute of Molecular and Cell Biology at the end of 1997. She then moved to Hong Kong University of Science and Technology in 2003 and became tenured associate professor in 2005. In 2006, she moved to the Department of Biological Sciences and Biotechnology (current School of Life Sciences), Tsinghua University as a professor, and served as the vice dean of School of Life Sciences in Tsinghua University between 2009 and 2015. She was awarded Changjiang Scholar from the Ministry of Education (China) and Outstanding Young Talent from the National Natural Science Foundation of China. Dr. Li is currently a professor of School of Life Sciences and senior investigator of Tsinghua-Peking Center for Life Sciences in Tsinghua University. She was elected Academician of the Chinese Academy of Sciences in 2015.

Dr. Li's research interest is in the area of lipid metabolism and the development of metabolic diseases, including obesity and fatty liver disease with special focus on the biogenesis, fusion and growth of lipid droplets. During the past many years, Dr. Li has made many outstanding contributions in the area of lipid metabolism.

\section{Identification of novel family of proteins that con- trol lipid metabolism and the development of met- abolic diseases}

Metabolic disorders, including obesity, hyperlipidemia, insulin resistance, liver steatosis and hypertension, are a group

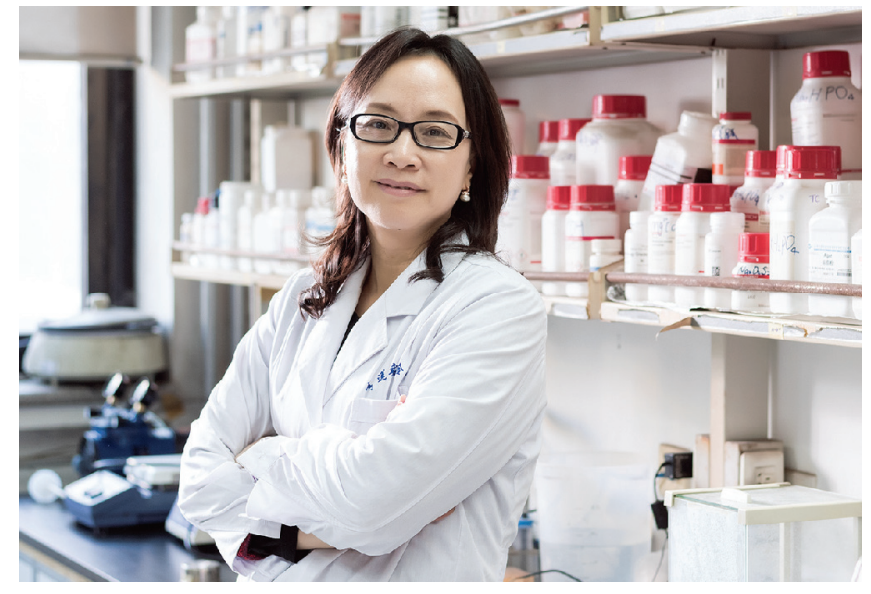

of diseases associated with metabolic malfunction and unbalanced energy homeostasis. Dr. Li has pioneered in the research of the biological functions and the underlying mechanisms in controlling lipid metabolism and the development of metabolic disorders for CIDE (cell deathinducing DFFA (DNA fragmentation factor, alpha subunit)like effector) family proteins. They have identified CIDE family proteins as ER and lipid droplet (LD)-associated proteins with highly restricted expression in adipose tissue, liver, skin sebocytes and pregnant and lactated mammary epithelia cells. By using genetically modified animal models and various biochemical and cell biology techniques, she and her colleagues have demonstrated that CIDE proteins are important regulators in the development of obesity, diabetes and liver steatosis by controlling various lipid metabolic pathways including lipid storage, LD fusion and growth in adipocytes and hepatocytes, lipid secretion in mammary epithelia cells and skin sebocytes, AMPK activity and VLDL secretion in hepatocytes (Li et al., 2007; Qi et al., 2008; Toh et al., 2008; Wang et al., 2012; Ye et al., 2009; Zhang et al., 2014; Zhou et al., 2003). Their research also suggest that CIDE proteins may serve as potential molecular targets for the screening of pharmacological agents for the prevention and treatment of metabolic disorders. 


\section{Delineating the molecular basis of LD fusion and growth}

LDs, dynamic cellular organelles present in most eukaryotic cells, play important roles not only in controlling lipid storage but also in many biological processes including virus packaging, intracellular protein metabolism and trafficking, and insulin signaling. However, the molecular components that determine biogenesis and growth of LDs as an organelle are poorly understood. Dr. Li and colleagues have demonstrated that CIDE family proteins are specifically clustered and enriched at the LD contact site (LDCS) where they initiate a unique atypical fusion by promoting lipid exchange and lipid transfer from smaller to larger LDs (Gong et al., 2011). CIDE-mediated LD fusion and growth is essential for the formation of unilocular LD formation and maximal lipid storage in adipocytes. It is also important in enhancing lipid storage in hepatocytes, mammary epithelia cells and skin sebocytes ( $\mathrm{Li}$ et al., 2007; Wang et al., 2012; Zhang et al., 2014). Furthermore, Dr. Li and colleagues have identified several other factors and signaling circuits that control LD fusion and lipid storage in adipocytes, including Plin1, Rab8a, AS160 and MSS4 (Sun et al., 2013; Wu et al., 2014).

Dr. Li has published more than 60 papers on world top journals and her research cited more than 9000 times. Her original and systematic research has earned her a pioneering role and international reputation in the field of lipid metabolism and metabolic diseases. She is the co-editor of the volume "Lipid Droplets" in Methods in Cell Biology. She has been an invited speaker of many international conferences, including Gordon Research Conference, the FASEB Science Research Conference, and the Cold Spring Harbor Asia Conference. She has organized many international conferences in lipid research and severed as an editorial board member of several international journals. Dr. Li is the project leader of the Innovative Group Research of the National Natural Science Foundation of China for "Lipid Homeostasis and Lipid Droplet", and the chief scientist of the National Basic Research Project on "Regulation of Lipid Metabolism and the Physiology and Pathology of Obesity". She has served as the scientific advisory board member of the National Natural Science Foundation of China and the council member of The Biophysical Society of China. Dr. $\mathrm{Li}$ has received important awards including Singapore Young Scientist award in 1999, the Arthur Kornberg Memorial lecture award by A-IMBN in 2008, and Ho Leung Ho Lee Foundation prize for Scientific and Technological Progress in Life Sciences in 2012.

Gong, J., Sun, Z., Wu, L., Xu, W., Schieber, N., Xu, D., Shui, G., Yang, H., Parton, R.G., and Li, P. (2011). Fsp27 promotes lipid droplet growth by lipid exchange and transfer at lipid droplet contact sites. J Cell Biol 195, 953-963.

Li, J.Z., Ye, J., Xue, B., Qi, J., Zhang, J., Zhou, Z., Li, Q., Wen, Z., and Li, P. (2007). Cideb regulates diet-induced obesity, liver steatosis, and insulin sensitivity by controlling lipogenesis and fatty acid oxidation. Diabetes 56, 2523-2532.

Qi, J., Gong, J., Zhao, T., Zhao, J., Lam, P., Ye, J., Li, J., Wu, J., Zhou, H., and Li, P. (2008). Downregulation of AMP-activated protein kinase by Cidea-mediated ubiquitination and degradation in brown adipose tissue. EMBO J 27, 1537-1548.

Sun, Z., Gong, J., Wu, H., Xu, W., Wu, L., Xu, D., Gao, J., Wu, J., Yang, H., Yang, M., and Li, P. (2013). Perilipin1 promotes unilocular lipid droplet formation through the activation of Fsp27 in adipocytes. Nat Commun 4, 1594.

Toh, S.Y., Gong, J., Du, G., Li, J., Yang, S., Ye, J., Yao, H., Zhang, Y., Xue, B., Li, Q., Yang, H., Wen, Z., and Li, P. (2008). Up-regulation of mitochondrial activity and acquirement of brown adipose tissue-like property in the white adipose tissue of fsp27 deficient mice. PLoS One 3, e2890.

Wang, W., Lv, N., Zhang, S., Shui, G., Qian, H., Zhang, J., Chen, Y., Ye, J., Xie, Y., Shen, Y., Wenk, M.R., and Li, P. (2012). Cidea is an essential transcriptional coactivator regulating mammary gland secretion of milk lipids. Nat Med 18, 235-243.

Wu, L., Xu, D., Zhou, L., Xie, B., Yu, L., Yang, H., Huang, L., Ye, J., Deng, H., Yuan, Y., Chen, S., and Li, P. (2014). Rab8a-AS160-MSS4 regulatory circuit controls lipid droplet fusion and growth. Dev Cell 30, 378-393.

Ye, J., Li, J., Liu, Y., Li, X., Yang, T., Ma, X., Li, Q., Yao, Z., and Li, P. (2009). Cideb, an ER- and lipid droplet-associated protein, mediates VLDL lipidation and maturation by interacting with apolipoprotein B. Cell Metab 9, 177-190.

Zhang, S., Shui, G., Wang, G., Wang, C., Sun, S., Zouboulis, C.C., Xiao, R., Ye, J., Li, W., and Li, P. (2014). Cidea control of lipid storage and secretion in mouse and human sebaceous glands. Mol Cell Biol 34, 1827-1838.

Zhou, Z., Yon Toh, S., Chen, Z., Guo, K., Ng, C.P., Ponniah, S., Lin, S., Hong, W., and Li, P. (2003). Cidea-deficient mice have lean phenotype and are resistant to obesity. Nat Genet 35, 49-56.

Open Access This article is distributed under the terms of the Creative Commons Attribution License which permits any use, distribution, and reproduction in any medium, provided the original author(s) and source are credited. 